\title{
A comparative study between laparoscopic intraperitoneal onlay mesh hernioplasty and open underlay mesh hernioplasty for ventral hernias
}

\author{
Adla Satya Narayan Rao, Ashwani Gupta, Debasis Naik*, \\ Gopalakrishnan Gunasekaran, Vimal Bhandari, Deepak Rajput
}

Department of General Surgery, V.M.M.C. and Safdarjung Hospital, New Delhi, India

Received: 23 April 2015

Revised: 09 May 2015

Accepted: 24 May 2015

*Correspondence:

Dr. Debasis Naik,

E-mail: debasismbbs@gmail.com

Copyright: ( ) the author(s), publisher and licensee Medip Academy. This is an open-access article distributed under the terms of the Creative Commons Attribution Non-Commercial License, which permits unrestricted non-commercial use, distribution, and reproduction in any medium, provided the original work is properly cited.

\begin{abstract}
Background: Even after nearly two decades of experience with laparoscopic ventral hernia repair, there is a surprising paucity of good data clearly proving the benefits of this technique over standard open procedure. The aim of this prospective study was to analyse the surgical technique and perioperative outcomes of laparoscopic intraperitoneal onlay mesh hernioplasty in comparison with the open underlay mesh hernioplasty for ventral hernias. Methods: Sixty patients with ventral hernia included in this study were divided into two groups after randomisation. Study group patients underwent laparoscopic intraperitoneal mesh hernioplasty and control group patients underwent open underlay mesh hernioplasty. Follow-up was done for a period of 6 months and the intraoperative and postoperative outcomes were compared.

Results: Patients operated by laparoscopic ventral hernia repair and open underlay mesh hernioplasty were comparable with respect to age, sex, comorbidities, previous history of abdominal surgery, body mass index and size of defect. The laparoscopic approach was associated with shorter operative time, lower blood loss and lesser postoperative pain requiring opioid analgesics for a shorter duration compared to the open approach. Also the length of hospital stay and duration of antibiotic requirement was less with laparoscopic approach. Incidence of seroma and recurrence was lower in the laparoscopic group.

Conclusions: Laparoscopic ventral hernia repair although technically demanding, is safe and feasible. It has fewer complications and a better postoperative course, with shorter operative time, less blood loss, lesser postoperative pain, quicker ambulation and shorter duration of hospital stay.
\end{abstract}

Keywords: Laparoscopic intraperitoneal onlay mesh hernioplasty, Open underlay mesh hernioplasty, Ventral hernia, Seroma, Recurrence

\section{INTRODUCTION}

A hernia is defined as an area of weakness or complete disruption of the fibromuscular tissues of the body wall. Hernias are among the oldest known afflictions of humankind. The word "hernia" is derived from a Latin term meaning "a rupture". The earliest reports of abdominal wall hernias date back to 1500 BC. During this early era, abdominal wall hernias were treated with trusses or bandage dressings. Despite the high incidence, the technical aspects of hernia repair continue to evolve. ${ }^{1}$

Leblanc and booth published the first report of laparoscopic incisional hernia repair in 1993. Over the course of time, this approach has gained popularity with patients who seek a "minimally invasive" solution to their 
hernia problem and with surgeons who believe that the laparoscopic approach offers advantages over traditional repairs. ${ }^{1}$

Even after nearly two decades of experience with laparoscopic incisional hernia repair, there is a surprising paucity of good data clearly proving the benefits of this technique over standard open procedure. Although, the pioneers of LVH felt that this approach would be less invasive and therefore less painful than traditional surgery, many other advantages became apparent as the procedure was developed. ${ }^{1}$

We conducted a prospective study on 60 patients with ventral hernia, half of which were operated by laparoscopic intraperitoneal onlay mesh hernioplasty and the rest by open underlay mesh hernioplasty. The aims and objectives of the study being to compare the safety and effectiveness of laparoscopic and open ventral hernia repair based on intraoperative and postoperative outcomes.

\section{METHODS}

The present prospective study was conducted on 60 patients with ventral hernia in Department of Surgery, Vardhaman Mahavir Medical College and Safdarjung Hospital, New Delhi during the period from October 2012 to October 2013. Half of the 60 patients underwent laparoscopic intraperitoneal onlay mesh hernioplasty (Study group) and the rest underwent open underlay mesh hernioplasty (Control group).

\section{Patient selection}

\section{Inclusion criteria}

- All adults (15-65 years) irrespective of gender with ventral hernia.

- Ventral hernias with greatest dimension of defect $\geq 3$ $\mathrm{cm}$ and $\leq 8 \mathrm{~cm}$.

- $\quad \mathrm{BMI} \leq 40 \mathrm{~kg} / \mathrm{m}^{2}$.

\section{Exclusion criteria}

- Patients in whom pneumoperitoneum is contraindicated.

- $\quad$ Patients unfit for General Anaesthesia.

- Peripheral hernias (situated close to the coastal margin or ilio-pubic tract) where $5 \mathrm{~cm}$ of overlap is not possible.

- Any condition where difficult intraperitoneal access is anticipated.
- Obstructed or strangulated hernia.

\section{Pre-operative management}

Patients with ventral hernias were worked up in the Surgery OPD with all routine investigations along with chest X-ray and ECG. Patients found fit for the surgery were admitted in the hospital an evening prior to surgery. Informed consent for laparoscopic mesh hernioplasty and its probable conversion to open surgery was taken. Relevant part preparation was done and test dose of cefazoline antibiotic and lignocaine were given along with inj. TT $(0.5 \mathrm{ml})$ i.m. stat. The size of the hernial defect was assessed clinically, however the exact size of the defect was determined intraoperatively. The defect was located and outlined, the size of mesh that is to be used was calculated and marks were made on the abdomen at the centre of the defect and probable outline of the mesh and positions of the transfascial sutures (Figure $1 \& 2$ ).

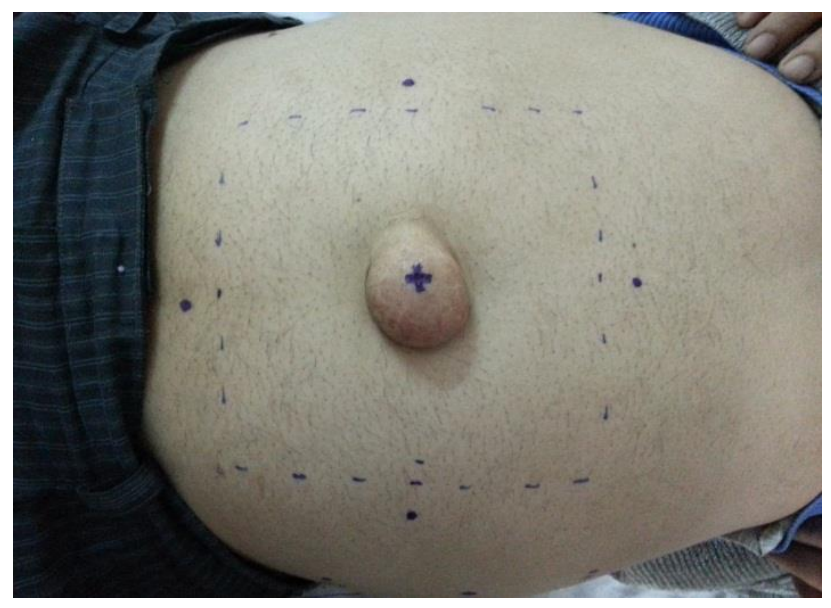

Figure 1: Preoperative markings on the anterior abdominal wall showing the sites of transfascial sutures.

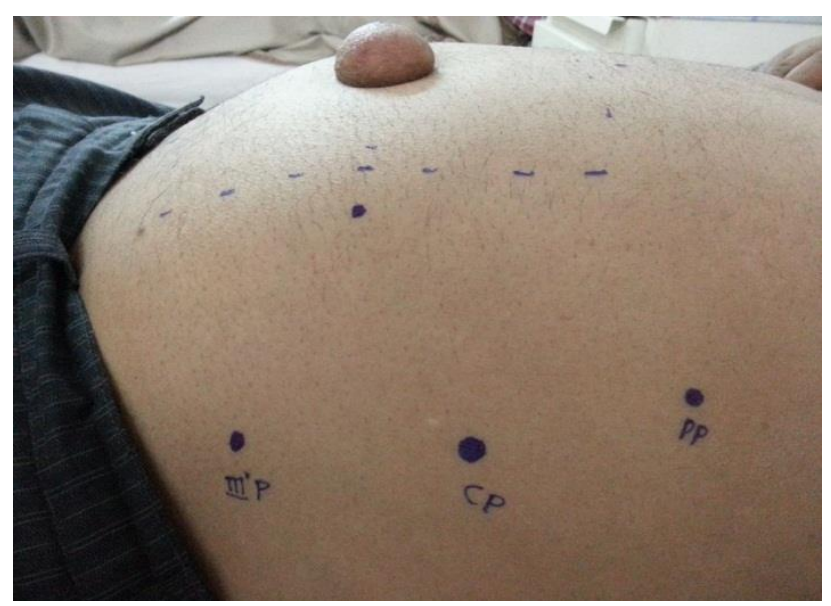

Figure 2: Preoperative markings on the anterior abdominal wall showing the sites of ports. PP Palmer's point (10mm port), CP - Camera port $(10 \mathrm{~mm})$ and III P - Third (hand) port $(5 \mathrm{~mm})$. 
Pre-operatively the following parameters were assessed:

- Age

- $\quad$ Sex

- Body mass index

- Number of previous abdominal operations.

- Laboratory parameters $(\mathrm{Hb} \%$, Platlet Count, S. Albumin, INR).

\section{Intra-operative management}

Surgeries in both the groups were done under general anaesthesia with the patient lying supine and hands tucked at the sides. Antibiotic inj. cefazolin (1 g) was given prophylactically before the incision was made and often again if the operation continued for more than 2 hours. A diclofenac $100 \mathrm{mg}$ patch was applied to the patient's arm over the deltoid. An orogastric tube was placed for gastric decompression. Abdomen was cleaned, painted and drapped. Ioban drape was used routinely to avoid mesh to skin contact.

\section{Open underlay mesh hernioplasty}

In this, the sac was entered and all adhesions were completely taken down from the sac and from the peritoneal surface in all directions. The edge of rectus sheath was opened and then the posterior rectus sheath and muscles were dissected, and rectus muscle and peritoneum in lower abdomen below the arcuate line. The posterior rectus sheath and peritoneum were closed primarily with 2'0 absorbable suture. Then an ultrapro (low weight polypropylene with polyglecapron) mesh of suitable size with a minimum of $3 \mathrm{~cm}$ overlap beyond the margin of the defect was placed over the posterior rectus sheath/peritoneum. The mesh was fixed by a series of "U" stitches through the mesh and then up through abdominal muscle on the anterior rectus sheath. The anterior rectus sheath was then closed with polypropylene. A drain was placed in the subcutaneous plane and the skin was closed.

\section{Laparoscopic intraperitoneal onlay mesh hernioplasty}

Pneumoperitoneum was created using a Veress needle at the Palmer's point which is the site of initial entry (either the left or right coastal margin at the tip of the $11^{\text {th }} \mathrm{rib}$, which usually corresponds to the anterior axillary line). After exploration of the abdomen, additional trocars were placed in the lateral abdominal wall, far enough from the edge of the hernia defect under direct vision.

The adhesions in the abdominal wall were lysed and the hernia contents were reduced using blunt and sharp dissection (Figure 3, 4 \& 5). Electrocautery was used sparingly to avoid inadvertent thermal injury to visceral organs. The hernia sac was left insitu. At this point, with the hernia contents reduced, the fascial edges of the hernia defect were identified circumferentially. Spinal needles placed perpendicular through the abdominal wall was used to mark the fascial edges. The pneumoperitoneum was evacuated and the defect was measured.

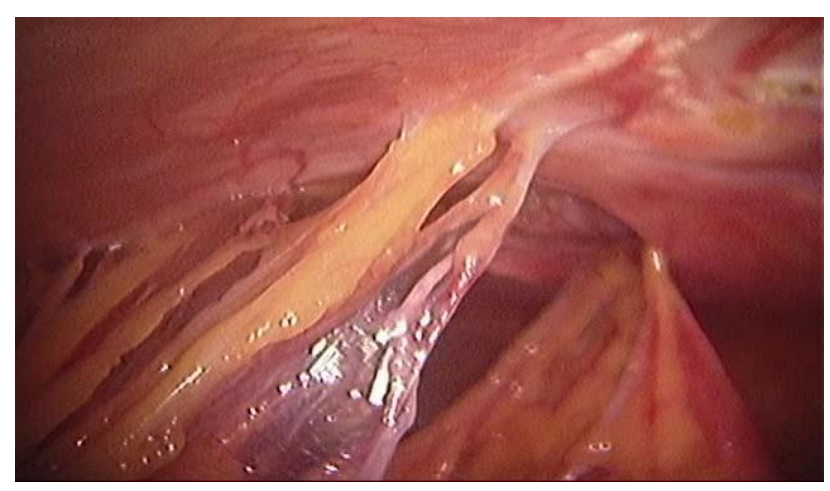

Figure 3: Laparoscopic view of the hernia defect with its content.

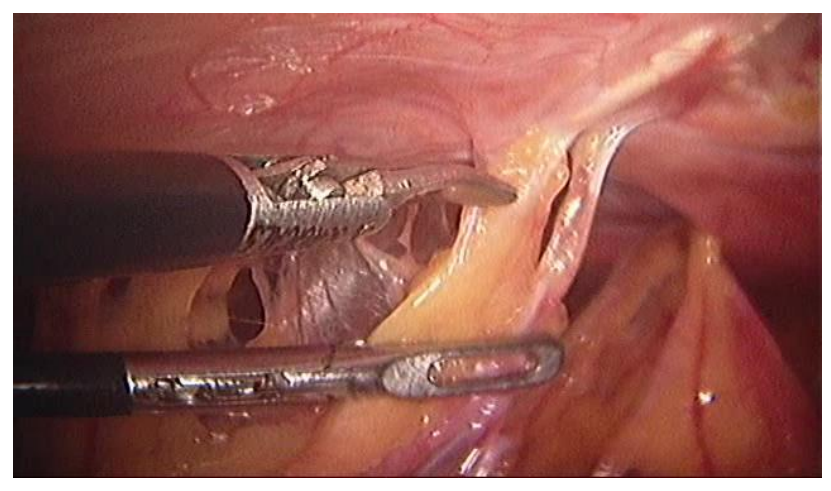

Figure 4: Adhesiolysis by blunt and sharp dissection with reduction of the contents.

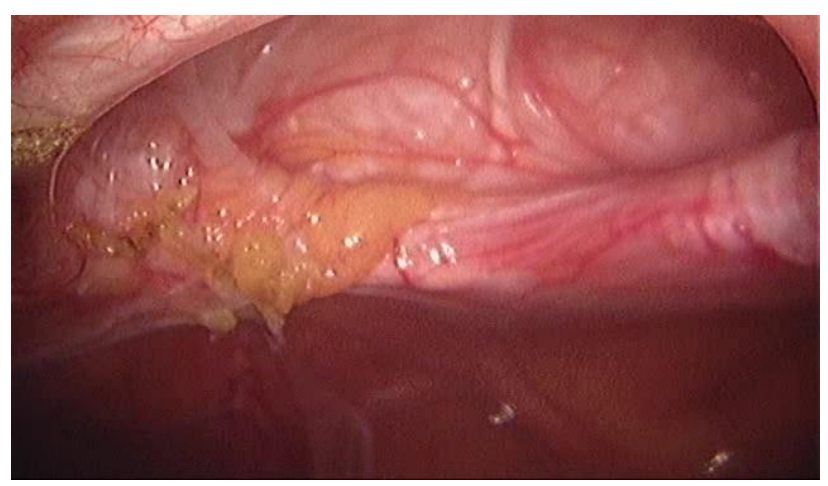

Figure 5: Fascial defect after adhesiolysis and reduction of contents.

To these measurements we added $6 \mathrm{~cm}$ in both directions to provide a minimum of $3 \mathrm{~cm}$ overlap of the fascial edges of the hernia by the mesh. A Proceed (low weight polypropylene with polydioxanone and oxidised 
regenerated cellulose) mesh (Figure 6) of appropriate size was introduced into the abdomen through the $10 \mathrm{~mm}$ port (Figure 7) after fixing four transfascial sutures to the midpoint of four edges of the mesh on the parietal surface. Mesh was unrolled (Figure 8) and the transfascial sutures were brought through the abdominal wall at predetermined positions using a suture passer (Figure 9) and tied with the knots buried in the subcutaneous plane. The perimeter of the mesh was then tacked to the abdominal wall at approximately $1 \mathrm{~cm}$ intervals (Figure 10) thereby preventing bowel and other abdominal contents from getting trapped above the mesh.

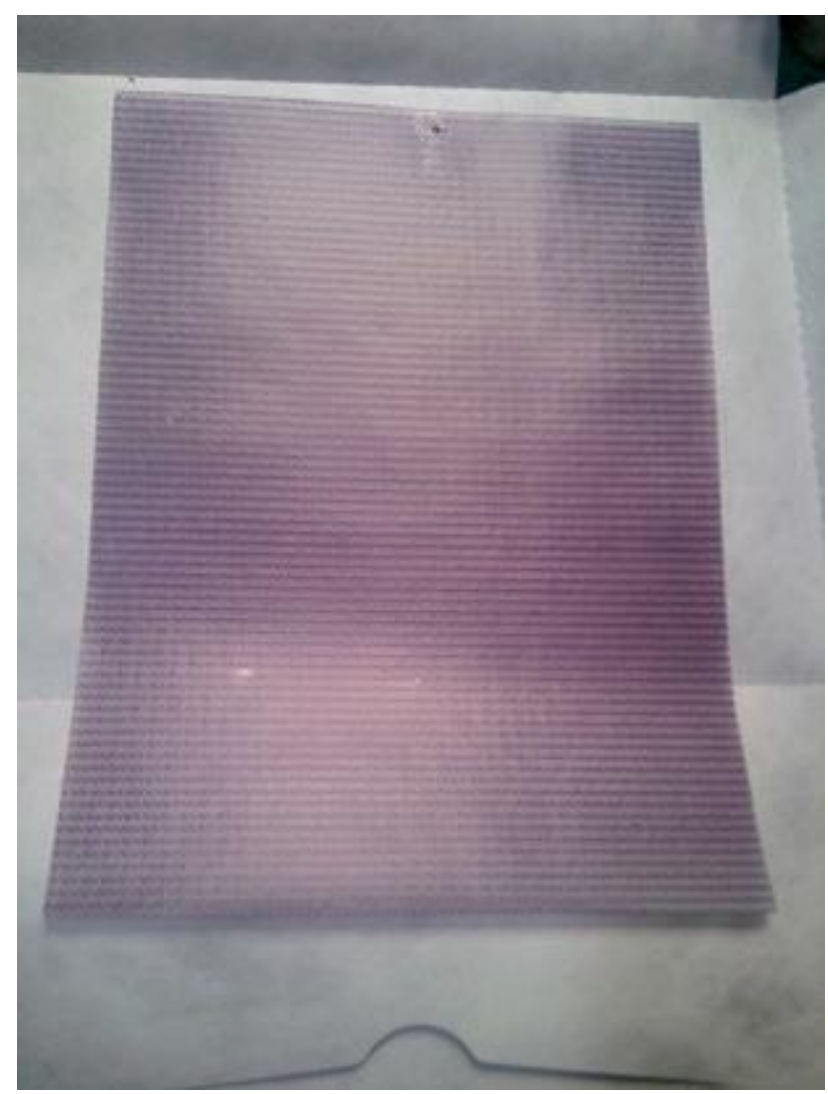

Figure 6: Proceed mesh (low weight polypropylene with polydioxanone and oxidised regenerated cellulose) showing the visceral surface.

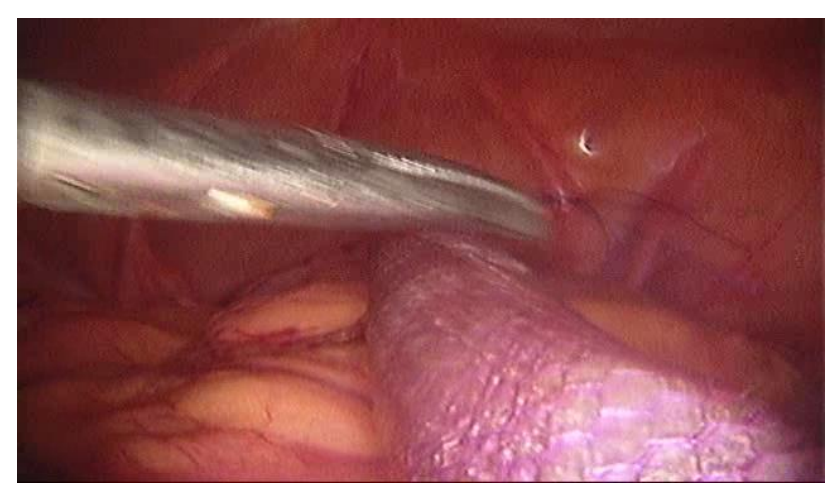

Figure 7: Rolled mesh introduced into the abdominal cavity through the camera port.

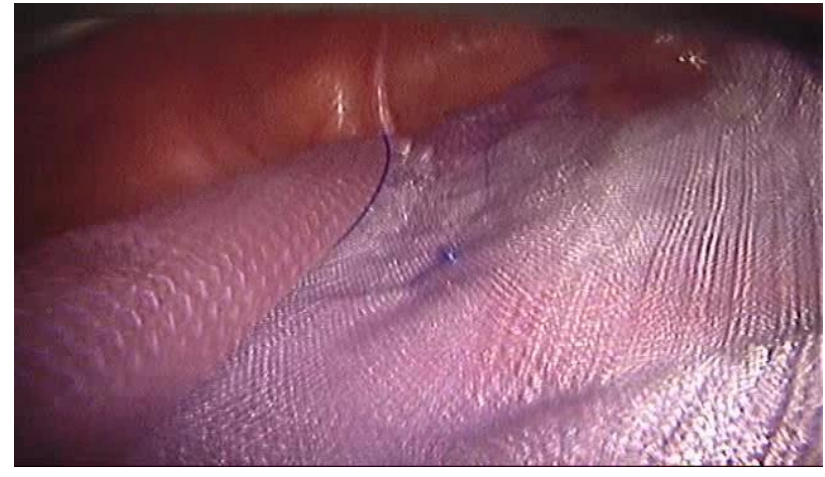

Figure 8: Mesh unrolled.

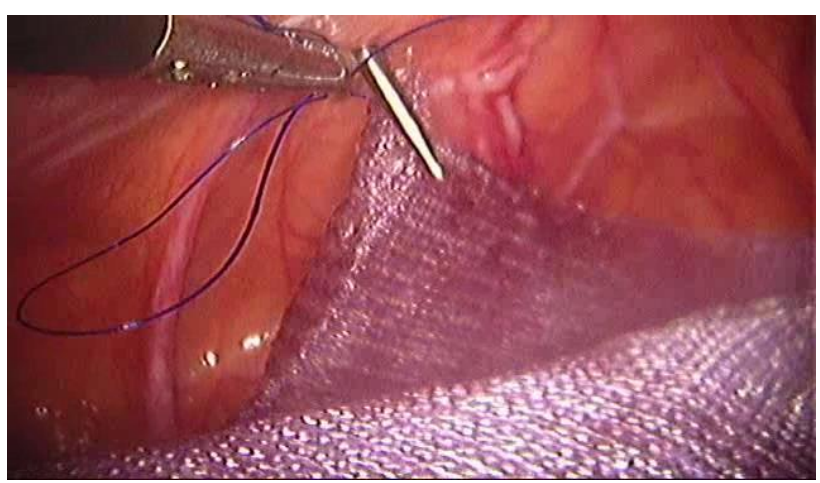

Figure 9: Mesh fixed to the abdominal wall with transfascial sutures using a suture passer.

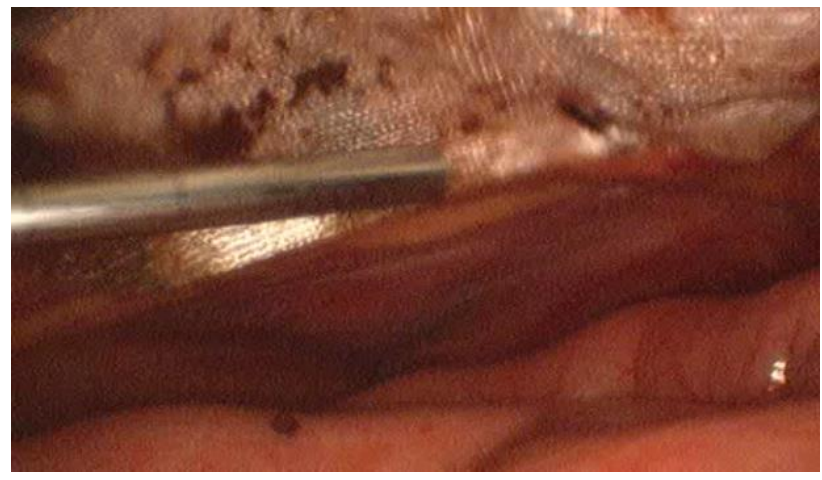

Figure 10: Tackers used to fix the mesh to the abdominal wall.

No drains were placed and the port sites were closed under vision.

Intra-operatively the following parameters were assessed:

- Size of the fascial defect

- Operating time - from the time of incision to the time of closure of the incision.

- Blood loss during surgery - by mop count.

\section{Post-operative management}

Post operatively patients were allowed to take sips of clear liquid after the recovery from general anaesthesia. 
In the evening of operation another transdermal Diclofenac patch of $100 \mathrm{mg}$ was applied on patient's arm over the deltoid on the opposite side. Subsequent analgesia was given as per the patient demand till the day of discharge.

Intravenous antibiotic (Inj. amoxicillin + potassium clavulanate $1.2 \mathrm{~g}$ ) was given twice a day for the duration the patient stayed in the hospital. Patients in the study group were discharged without any antibiotic while patients in the control group were discharge with oral antibiotic (Tab. amoxicillin + potassium clavulanate 625 $\mathrm{mg}$ ) for a duration of 5 days to prevent any wound infection.

Number of days in hospital was considered as the number of nights patient spent in hospital. Patient were allowed to take normal diet postoperatively after bowel sounds appeared and were advised to carry on their normal routine work as per as their level of comfort. Patients were discharged after they were allowed orally with visual analogue pain score $\leq 5$.

Regular follow up of the patient was done at the time period of 1 week, 1 month, 3 months and 6 months.

Post-operative pain and severity of pain was assessed daily using Visual analogue pain scale and the duration of opioid analgesic requirement.

Post-operative pain was assessed at the time of discharge and subsequent follow ups.

Wound infection and any other complication was assessed post-operatively.

Seroma formation was confirmed by ultrasound. Patients who developed seroma were managed conservatively without any intervention by oral antibiotic (Tab. amoxicillin + potassium clavulanate $625 \mathrm{mg}$ ) for a period of 5 days to prevent any secondary infection.

Recurrence was detected post-operatively and during subsequent follow ups within a period of 6 months.

Post-operatively the following parameters were observed:

- $\quad$ Pain Score at 24 hours and 48 hours.

- $\quad$ Analgesic requirement.

- Duration of antibiotic use.

- Length of hospital stay.

- Wound infection.

- Seroma formation.

- $\quad$ Recurrence within 6 months.

\section{Statistical analysis}

For categorical variations like recurrence and seroma formation Fischer's exact/Chi square test was used. For pain scoring which is on scale of 0 to10, student $t$ test was used.

For data which do not follow normal distribution non parametric Mann-Whitney test was used. Statistical difference between two groups was determined where approximately $\mathrm{p}$ score $<0.05$ will be regarded as significant. Statistical analysis was performed by using SPSS computer software.

\section{RESULTS}

Every operation attempted was completed without any complications. There were no conversions. The outcome was determined by following-up the patients of both the groups postoperatively upto 6 months.

\section{Demochartic details of the patient}

Age

The age distribution of patients in both the groups were comparable. Mean age of the patients in the study group was 40.8 years ( $\mathrm{SD}=9.3848$, median: 40 years, range: 26 to 65 years), while the mean age in the control group was 41.17 years $(\mathrm{SD}=9.7535$, median: 40.5 years, range 25 to 65 years) $\mathrm{p}=0.883$.

\section{Sex distribution}

The sex distribution in the two groups was insignificantly different. Study group, 10 males and 20 females vs. control group, 12 males and 18 females. $\mathrm{p}=0.789$.

\section{Comorbidities}

There was no significant differences in the comorbidities of patients in the two groups. Study group, 5 diabetic and 8 hypertensive patients vs. control group, 5 diabetic and 9 hypertensive patients. $\mathrm{p}=1.000$ for both diabetes and hypertension.

\section{Previous history of surgery}

In the study group, 10 patients had no previous history of abdominal surgery, 17 patients had history single abdominal surgery, 2 had history of two abdominal operations and 1 patient had history of three abdominal operations. Mean $=0.8$ and median $=1.0$. In the control group, 14 patients had no previous history of abdominal surgery, 14 patients had history of single abdominal surgery and 2 had history of two abdominal operation. Mean $=0.6$ and median $=1.0$. There was no significant difference, $\mathrm{p}=0.581$. 
Body Mass Index (BMI)

The mean BMI of the study population was $26.22 \mathrm{Kg} / \mathrm{m}^{2}$ (range, 18.38 to $36.32 \mathrm{Kg} / \mathrm{m}^{2}$, $\mathrm{SD}=3.6793$ ) while the mean BMI in the control population was $25.22 \mathrm{Kg} / \mathrm{m}^{2}$ (range, 19.60 to $\left.29.54 \mathrm{Kg} / \mathrm{m}^{2}, \mathrm{SD}=2.4561\right) . \mathrm{p}$ value $=$ 0.220 (insignificant).

\section{Haemoglobin (Hb\%)}

The mean Haemoglobin concentration was $12.04 \mathrm{~g} \%$ (range, 9.8 to $15.2 \mathrm{~g} \%$ ) and $12.45 \mathrm{~g} \%$ (range, 10.2 to 14.9 $\mathrm{g} \%$ ) in the study and control group respectively. $\mathrm{p}$ value $=0.278$ (insignificant).

\section{Platlet count}

The mean total platlet count was $196666.67 / \mathrm{mm}^{3}$ (range, 100000 to $287000 / \mathrm{mm}^{3}$, median $198500 / \mathrm{mm}^{3}$ ) and $211266.67 / \mathrm{mm}^{3}$ (range, 112000 to $402000 / \mathrm{mm}^{3}$; median $\left.191500 / \mathrm{mm}^{3}\right) . \mathrm{p}$ value $=0.291$ (insignificant). Thus, total platlet count in the study group and control group patients were comparable and shouldn't affect the blood loss.

\section{Serum albumin}

The mean Serum Albumin in the study group was 3.85 $\mathrm{g} / \mathrm{dL}$ (range, 3.5 to $4.6 \mathrm{~g} / \mathrm{dL}$; median $3.8 \mathrm{~g} / \mathrm{dL}$ ) and 3.93 $\mathrm{g} / \mathrm{dL}$ in the control group (range, 3.4 to $4.4 \mathrm{~g} / \mathrm{dL}$; median $3.9 \mathrm{~g} / \mathrm{dL}$ ). $\mathrm{p}=0.244$ (insignificant).

\section{International normalised ratio (INR)}

The mean INR was 1.025 (range, 0.86 to 1.18 ; median 1.02 ) in the study group and 1.033 (range, 0.86 to 1.24 ; median 1.01) in the control group. $\mathrm{p}$ value $=0.743$ (insignificant). Thus, International Normalised Ratio (INR) in the study group and control group patients were comparable and didn't affect the outcome i.e. blood loss during surgery.

\section{Intraoperative findings}

\section{Defect size}

The mean defect size in the study population was $5.13 \mathrm{~cm}$ (range, 3 to $8 \mathrm{~cm}$; median $5.0 \mathrm{~cm}$ ) and $4.83 \mathrm{~cm}$ (range, 3 to $8 \mathrm{~cm}$; median $4.5 \mathrm{~cm}$ ) in the control population. $\mathrm{p}$ value $=0.433$ (insignificant).

\section{Operating time}

The mean operating time (time period from the time of incision to time of closure of incision) was $75.33 \mathrm{~min}$ in the study group (range, 30 to $195 \mathrm{~min}$; median $75 \mathrm{~min}$ ) where as it was $150.83 \mathrm{~min}$ the control group (range, 75 to $240 \mathrm{~min}$; median $150 \mathrm{~min}$ ). $\mathrm{p}$ value $<0.0001$ (significant).

\section{Blood loss}

The mean estimated blood loss was $9.83 \mathrm{ml}$ (range, 5 to $20 \mathrm{ml}$; median $10 \mathrm{ml}$ ) and $116.33 \mathrm{ml}$ (range, 20 to 300 $\mathrm{ml}$; median $100 \mathrm{ml}$ ) for the study group and control group respectively. $\mathrm{p}$ value $<0.0001$ (significant).

\section{Pain score}

The mean pain score at 24 hour in the study group was 4.10 (range, 2 to 6 ; median 4) and 5.43 (range, 2 to 7; median 5) in the control group. p value $<0.0001$ (significant), Independent Sample t-test. Mean pain score at 48 hour was 2.47 (range, 1 to 4 ; median 2) and 3.67 (range 1 to 5: median 4) in study group and control group respectively. $\mathrm{p}$ value $<0.0001$ (significant).

Also, the percentage of change in the pain score from 24 hour to 48 hour was $40.89 \%$ and $33 \%$ in the Study group and Control group respectively. $\mathrm{p}=0.015$ (significant).

\section{Duration of opioid analgesic use}

The average duration of opioid analgesic use in the study group was 2.6 days (range, 1 to 4 days; median 3 days) while it was 3.5 days (range, 2 to 5 days; median 4 days) in the control group. $\mathrm{p}$ value $<0.0001$ (significant).

\section{Length of hospital stay}

Average hospital stay was 2.6 days (range, 1 to 4 days; median 3 days) in the study population where as it was 3.5 days (range, 2 to 5 days; median 4 days) in the control group. $\mathrm{p}$ value $<0.0001$ ( significant).

\section{Duration of antibiotics}

The average duration of antibiotic use in the study group was 2.77 days (range, 1 to 9 days; median 3 days) while it was 8.83 days (range, 7 to 14 days; median 9 days) in the control group. $\mathrm{p}$ value $<0.0001$ (significant).

\section{Seroma formation}

There was a single case of seroma formation in the study group noticed at 1 week of follow-up while there were 2 cases of seroma formation in the control group. These seromas resolved spontaneously and didn't require any intervention. However, prophylactic oral antibiotics were given for a period of 5 days to prevent their secondary infection.

Wound infection: There were no cases of wound infection in either group.

\section{Recurrence}

There were no recurrences in the study group during the follow-up period of 6 months while there was 1 recurrence in the control group. 
Table 1: Observation table.

\begin{tabular}{|lllll|}
\hline Observations & $\begin{array}{l}\text { Study } \\
\text { group }\end{array}$ & $\begin{array}{l}\text { Control } \\
\text { group }\end{array}$ & P value \\
\hline Mean Defect size (cm) & 5.13 & 4.83 & 0.433 \\
\hline Mean Operating time (min) & 75.33 & 150.83 & $<0.0001$ \\
\hline Mean Blood loss (ml) & 9.83 & 116.33 & $<0.0001$ \\
\hline \multirow{4}{*}{ Mean pain score } & At 24 hour & 4.10 & 5.43 & $<0.0001$ \\
\cline { 2 - 5 } & At 48 hour & 2.47 & 3.67 & $<0.0001$ \\
\cline { 2 - 5 } & Percentage decrease & 40.99 & 33 & $=0.015$ \\
\hline Mean duration of opioid analgesic (days) & 2.6 & 3.5 & $<0.0001$ \\
\hline Mean duration of hospital stay (days) & 2.6 & 3.5 & $<0.0001$ \\
\hline Mean duration of antibiotics (days) & 2.77 & 8.83 & $<0.0001$ \\
\hline Seroma formation (\%) & 3.33 & 6.66 & \\
\hline Recurrence (\%) in 6 months & 0 & 3.33 & \\
\hline
\end{tabular}

\section{DISCUSSION}

A hernia is defined as an abnormal protrusion of an organ or tissue through a defect in its surrounding walls. Although a hernia can occur at various sites of the body, these defects most commonly involve the abdominal wall. Abdominal wall hernias occur only at sites at which the aponeurosis or fascia are not covered by striated muscle. $^{2}$

Ventral hernias refer to hernias of the anterior abdominal wall. $^{3}$ These defects can be categorized as spontaneous or acquired or by their location on the abdominal wall. Epigastric hernias occur from the xiphoid process to the umbilicus, umbilical hernias occur at the umbilicus, and hypogastric hernias are rare spontaneous hernias that occur below the umbilicus in the midline. Acquired hernias typically occur after surgical incisions and are therefore termed incisional hernias. ${ }^{2}$

\section{Incidence and etiology}

Based on national operative statistics, incisional hernia account for $15 \%$ to $20 \%$ of all abdominal wall hernias; umbilical and epigastric constitute $10 \%$ of hernias. ${ }^{2}$

Umbilical hernias occur more commonly in adult females with a female: male ratio of 3:1. They are more commonly found in association with processes that increase the intra-abdominal pressure, such as pregnancy, obesity, ascites, persistent or repetitive abdominal distension in bowel obstruction, or peritoneal dialysis. Epigastric hernia on the other hand is more common in males by a ratio of $3: 1$.

Of all hernias encountered, incisional hernias are the most frustrating and difficult to treat. Incisional hernia occurs as a result of excessive tension and inadequate healing of a previous incision, which may be associated with surgical site infection. Incisional hernias are twice as common in women as in men. ${ }^{2}$ Factors predisposing to their development are patient factors (obesity, general poor healing due to malnutrition, immunosuppression or steroid therapy, chronic cough, cancer), wound factors (poor quality tissues, wound infection) and surgical factors (inappropriate suture material, incorrect suture placement). ${ }^{3}$

Technical aspects of wound closure likely contribute to incisional hernia formation. Wound closed under excessive tension are prone to fascial closure disturbance. Therefore a continuous closure is advocated to disperse the tension throughout the length of the wound. In this way, $1 \mathrm{~cm}$ bites of fascia on either side of the incision are taken with each pass of suture and the suture is advanced $1 \mathrm{~cm}$ at a time along the length of the incision ${ }^{1}$.

\section{Diagnosis}

The evaluation of abdominal wall hernia requires diligent physical examination. As with inguinal region, the anterior abdominal wall is evaluated with the patient in standing and supine positions, and a Valsalva maneuver is also useful to demonstrate the site and size of hernia. Imaging modalities like ultrasound and computed tomography play a greater role in the diagnosis of more unusual hernias of the abdominal wall. ${ }^{2}$

\section{Treatment: operative repair}

Primary repair of hernias can be done when the defect is small ( $\leq 2$ to $3 \mathrm{~cm}$ in diameter) and there is viable surrounding tissue. Large defects $(>2$ to $3 \mathrm{~cm}$ in diameter) have a high recurrence rate if closed primarily and are repaired with prosthesis. Recurrence rates vary between $10 \%$ and $50 \%$ and are typically reduced by more than $50 \%$ with the use of prosthetic mesh. Prosthetic 
material may be placed as Onlay, Inlay or Sublay (Underlay). ${ }^{2}$

Onlay technique involves primary closure of the fascia defect and placement of a mesh over the anterior fascia. Being placed outside the abdominal cavity it has the advantage of avoiding direct interaction with the abdominal viscera. However, disadvantages include large subcutaneous dissection, increases likelihood of seroma formation and superficial location of the mesh. It has reported a recurrence rate of $28 \% .^{2}$

Inlay prosthetic repair involves securing the mesh to the fascial edge without overlap. This results in a predictably high recurrence rate because the synthetic often pulls away from fascial edge because of increased intraabdominal pressure. $^{2}$

The Sublay or Underlay technique involves placing the prosthetic below the fascial components. The mesh can be placed intraperitoneally, preperitoneally, or in the retrorectus (retromuscular) space. With wide overlap of mesh and fascia, the natural forces of the abdominal cavity act to hold the mesh in place and prevent migration. Long term studies have shown respectable recurrence rate of $14 \% .^{2}$

Laparoscopic incisional hernia repair was first reported by Leblanc and Booth in 1993. Over the course of time, this approach has gained popularity with patients who seek a "minimally invasive" solution to the hernia problem and with surgeons who believe that the laparoscopic approach offers advantages over traditional repairs. Laparoscopic approach is associated with low incidence of hernia recurrence in the range of $0-11 \% .^{1}$

Laparoscopic ventral hernia repair is based on the principles of the Rives-Stoppa repair in which the mesh is placed deep to the hernia defect and fixed with wide mesh coverage to healthy abdominal wall fascia using point fixation and full thickness permanent sutures. The laparoscopic ventral hernia repair differs from open underlay mesh hernioplasty in that the mesh is placed inside the peritoneal cavity rather than the retro-rectus position ${ }^{4}$.

One of the most common technical cause of failure with traditional hernia repairs is failure to identify all fascial defects. Many incisional hernias have multiple components, some of which are not apparent on physical examination. If a surgeon fails to repair all the defects, failure is almost certain to occur. Additional advantages of laparoscopic ventral hernia repair are, it may identify unsuspected intraperitoneal pathology and that it approaches the defect transperitoneally, avoiding tedious dissection of subcutaneous layers. ${ }^{1}$

Because of the extensive dissection required for the development of flaps in this open hernia repair, the operation is associated with greater blood loss and marked risk of morbidity. Wound complications or infection rates of $12 \%$ to $20 \%$ have been reported. The elimination of the need for broad tissue dissection and drain placement in $\mathrm{LVH}$ is the reason that the infection related complication rate is low. ${ }^{5}$

The laparoscopic approach to incisional hernia shares the general complications of laparoscopy. ${ }^{3}$ One of the most common complication of $\mathrm{LVH}$ is seroma formation ${ }^{5}$. It is seen in almost all patients but is significant in only approximately $8 \%$ of them. ${ }^{6}$ Most seromas develop above the mesh and within the retained hernia sac. The majority resolve spontaneously without any intervention. Another known serious complication in patients who have previously undergone abdominal surgery is enterotomy. ${ }^{5}$ The enterotomy rate as per literature is $1.8 \% .^{6}$ The principal strategy to avoid bowel injury is to take advantage of pneumoperitoneum as a retraction instrument and to employ sharp dissection with limited use of electrothermal cautery. ${ }^{5}$ Persistent pain at suture site is noted in about $1.5 \%$ of the patients. ${ }^{6}$

There were no incidences of wound infection in either group. The recurrence rate in the study group was $0 \%$ and in the control was $3.33 \%$ in the follow-up time of 6 months. These low figures might be due to our short period of follow-up.

\section{CONCLUSION}

From our study we can arrive at the following conclusions:

1. Laparoscopic approach is associated with shorter operative time.

2. This procedure results in significantly lower blood loss than the open procedure.

3. Postoperative pain is less.

4. It is associated with shorter hospital stay and shorter duration of opioid analgesic requirement.

5. The antibiotic requirement is also less in this group.

6. It has lower incidence of seroma formation.

7. It has lower rate of recurrence in short term followup.

\section{Limitations of this study}

1. Short term follow-up which cannot be used to determine the exact rate of recurrence because approximately $66 \%$ to $90 \%$ of ventral hernia recurrences develop within 2 years after operation. 


\section{ACKNOWLEDGEMENTS}

We are thankful to the Medical Superintendent and Head of Department of Surgery, Safdarjung Hospital. We are also thankful to the staffs of Department of Surgery and Medical Records Department for their support throughout the study.

Funding: No funding sources

Conflict of interest: None declared

Ethical approval: Approved

\section{REFERENCES}

1. Michael J. Zinner, Stanley W. Ashley. Hernias. In: Michael J. Zinner, Stanley W. Ashley, eds. Maingot's Abdominal Operations. 12th ed. China: McGraw-Hill; 2013: 123-159.

2. M. Townsend, R. Daniel Beauchamp, B. Mark Evers, Kenneth L. Mattox. Hernias. In: M. Townsend, R. Daniel Beauchamp, B. Mark Evers, Kenneth L. Mattox, eds. Sabiston Textbook of Surgery: The Biologic Basis of Modern Surgical
Practice. 19th ed. Philadelphia: Elsevier; 2013: 1114-1138.

3. Norman S. Williams, Christopher J.K. Bulstrode, P. Ronan O Connell. Abdominal wall, hernia and umbilicus. In: Norman S. Williams, Christopher J.K. Bulstrode, P. Ronan O Connell, eds. Bailey and Love's Short Practice of Surgery. 26th ed. Florida: CRC Press; 2013: 948-969.

4. Josef E. Fischer. Laparoscopic ventral hernia repair. In: Josef E. Fischer, eds. Fischer's Mastery of Surgery. 6th ed. Philadelphia: Lippincott Williams and Wilkins; 2012: 2139-2142.

5. B. Todd Heniford, Adrian Park, Bruce J. Ramshaw, Guy Voeller. Laparoscopic repair of ventral hernias: nine year's experience with 850 consecutive hernias. Ann Surg. 2003;238(3):391-8.

6. Karl A, LeBlanc. Incisional hernia repair: laparoscopic techniques. World J Surg. 2005;29:1073-9.

Cite this article as: Rao ASN, Gupta A, Naik D, Gunasekaran G, Bhandari V, Rajput D. A comparative study between laparoscopic intraperitoneal onlay mesh hernioplasty and open underlay mesh hernioplasty for ventral hernias. Int Surg J 2015;2:352-60. 